\title{
Credit-Based Insurance Scores and the Cost to Consumers
}

\author{
Cleveland Stiff \\ Prairie View A\&M University \\ Reginald L. Bell \\ Prairie View A\&M University \\ Sudhir Tandon \\ Prairie View A\&M University
}

A CS (CS) can determine whether a consumer will or will not receive a loan for an automobile, house, or small business. The interest rate banks charge for loans, credit cards, and some employment opportunities, are dependent on a CS. CSs directly affect the cost of all types of insurance coverage, especially property and casualty. Insurance carriers are permitted by law in most States to use CreditBased Insurance Score (CBIS) to determine premiums. The CS is not the same as the CBIS. We explicate the difference between a CS and a CBIS in this article. We help consumers of insurance products better understand how insurance carriers determine premiums based on CBIS. We share 10 recommendations tips to help consumers raise their CS's and lower the cost of their insurance premiums by improving their $C B I S$. We also make recommendations involving other premium rating factors that may help in the event that their CS is compromised.

Keywords: Insurance, CSs, Factors, Reporting, Disputes, Premiums, FICO

\section{INTRODUCTION}

In 1956 the Fair Isaac Corporation (FICO), founded by Bill Fair and Earl Isaac, developed a measure for consumer risk; their analysis showed a correlation between credit characteristics and insurance losses (FICO, 2019). A Credit-Based Insurance Scores (CBIS) of the 1990's follows a similar logic; it uses certain elements of a person's credit history to predict how likely that person would be associated with causing an insurance loss to the carrier. The CBIS became a benchmark within the insurance industry. The CBIS continues to be trusted by insurance carriers: $95 \%$ of automobile carriers and $85 \%$ of homeowners' carriers use the CBIS. In states where it is legal, carriers calculate risk classification factors when underwriting policies using characteristics from an individual's CS (CBIS, 2012).

Credit history also plays a larger role in determining your insurance rate than most consumers realize. In a summary article of a Consumer Reports article by Margot Gilman, Hennelly (2015, para 1) quotes Gilman as saying, "In the vast amounts of states, a poor credit history will have a greater impact on your auto insurance premium than a drunk-driving conviction". In New York State, an excellent CS saves drivers $\$ 255$ more per year than those drivers with merely a good CS. Insurance carrier know there is a 
direct statistical relationship between financial stability of the consumer and a loss to the carrier. They have a history of data demonstrating that insured persons who have higher levels of financial responsibility have fewer losses, and subsequently, should pay less for their insurance. Insurance companies will use a credit score (CS) to decide whether they should issue a policy, and on what terms. A higher CS equates to less risk for the carrier. Less risk to the carrier means a higher likelihood a person will receive insurance coverage and pay less for the policy.

\section{What Is Credit Scoring?}

Is it legal for an insurance company to use an individual's credit information without permission? The short answer is "yes." The federal law, The Fair Credit Reporting Act (FCRA), states that insurance companies have a "permissible purpose" to look at your credit information without your permission. Credit scoring is a system used by creditors to assist in determining whether to extend credit. It is also used to help decide the rate one will pay and the terms, once credit is granted. Certain information is collected from a consumer's credit report and maybe used as determinant in extending credit. The determinants include; bill paying history, the type and number of accounts one has, whether one pays his or her bills by the due date, outstanding debt, age of accounts, and collection actions. Using a statistical model, creditors compare the information to the loan repayment history of consumers with similar profiles. For example, a credit scoring system awards points for each factor that helps predict who is likely to repay debt. A total number of points, a CS, helps predict how trustworthy a consumer may be. The CS is a predictor of how likely it is that the consumer will repay a loan and make the payments by the due date.

Credit report information, along with other factors are also used by some insurance companies to predict the likelihood of filing an insurance claim and the severity of the claim. The carriers may consider the information in determining whether to provide coverage and the premium to be charged. The CSs insurance companies' use sometimes are called "insurance scores" or "CBIS" (Credit Scores, 2013).

\section{Are Credit Scoring Systems Reliable?}

Credit scoring systems enable creditors and insurance companies to evaluate millions of applicants consistently on many different characteristics. The use of credit scoring systems requires the sample to be large enough to be statistically valid.

Credit scoring systems enable faster, more accurate, and more impartial decisions than individual reviewers or underwriters can make.

\section{How Does a CBIS Differ from a Regular CS?}

A regular CS looks at many different factors to determine how likely you are to repay a loan or a line of credit. A CBIS score looks at some, but not all, factors in your credit history to determine how you are likely to manage your risk exposure. Insurance companies can only use your CBIS as one factor in its underwriting process. Your score will be considered with several other factors that vary by insurance type. For example, with homeowners insurance other factors could be your zip code; the age of the home; age of the roof, and the number of pass claims.

\section{What Kind of Information Goes into a CBIS?}

There are several different companies that create credit-based insurance score reports for insurers to use. FICO looks at five general areas it believes will best determine how you manage risk. Table 1 shows the breakdown of what is considered and what types of information, and to what degree, is generally weighed in figuring your credit-based insurance score (CBIS) on "How an Insurance Company Can Use Your Credit to Determine Your Premium" (2012). 


\section{TABLE 1 \\ INFORMATION WEIGHED IN FIGURING YOUR CREDIT-BASED INSURANCE SCORE}

\begin{tabular}{|l|l|}
\hline Payment History (40\%) & $\begin{array}{l}\text {-How well you have made payments on your outstanding debt in the } \\
\text { past }\end{array}$ \\
\hline Outstanding Debt (30\%) & - How much debt you currently have \\
\hline $\begin{array}{l}\text { Credit History Length (15\%) } \\
\text { Pursuit of New Credit (10\%) }\end{array}$ & - - If you long you have had a line of credit \\
\hline Credit Mix (5\%) & $\begin{array}{l}\text { - The types of credit you have (credit card, mortgage, auto loans, } \\
\text { etc.) }\end{array}$ \\
\hline $\begin{array}{l}\text { Source: National Association of Insurance Commissioners (2012). } \\
\text { https://www.naic.org/documents/consumeralert_credit_based_insurance_scores.htm }\end{array}$ \\
\hline
\end{tabular}

\section{WHAT CAN YOU DO TO IMPROVE YOUR SCORE?}

Improving your score significantly is likely to take some time, but it can be done. According to the Federal Trade Commission, Consumer Information, the best ways to improve your CS under most systems, is to: 1) focus on paying your bills in a timely way, 2) pay down any outstanding balances, and 3) stay away from new debt (Credit Scores, 2019). Credit scoring systems are complex systems. If one factor changes, your score may change.

Improvement generally depends on how that factor relates to others the system considers. Only the insurance company using the system knows what will improve your score under the particular model they use. Scoring models may be based on more than the information in your credit report. When you are applying for a mortgage loan, for example, the system may consider the amount of your down payment, your total debt, and your income, among other things. Table 2 presents the five main categories usually considered in an individual's credit report to help compute a CS.

TABLE 2

\section{MAIN CATEGORIES USED IN SCORING MODELS WHEN FIGURING ACS}

\begin{tabular}{|l|l|}
\hline $\begin{array}{l}\text { Timely } \\
\text { Payments }\end{array}$ & $\begin{array}{l}\text { If your credit report indicates that you have late payments, accounts referred to } \\
\text { collections, or bankruptcy, it will affect your score negatively. }\end{array}$ \\
\hline Credit Limits & $\begin{array}{l}\text { If the amount you owe is close to your credit limit, it's likely to have a negative effect } \\
\text { on your score. }\end{array}$ \\
\hline Credit History & $\begin{array}{l}\text { Scoring systems consider your credit track record. A short credit history may affect } \\
\text { your score negatively, but factors like on time payments and low balances can offset } \\
\text { that. }\end{array}$ \\
\hline $\begin{array}{l}\text { Credit } \\
\text { Inquiries }\end{array}$ & $\begin{array}{l}\text { Scoring systems consider whether you have applied for credit recently by looking at } \\
\text { "inquiries" on your credit report. If you have applied for too many new accounts } \\
\text { recently, it could have a negative effect on your score. }\end{array}$ \\
\hline $\begin{array}{l}\text { Limit Credit } \\
\text { Accounts }\end{array}$ & $\begin{array}{l}\text { Although it is generally considered a plus to have established credit accounts, too } \\
\text { many credit card accounts may have a negative effect on your score. In addition, } \\
\text { many scoring systems consider the type of credit accounts you have. For example, } \\
\text { under some scoring models, loans from finance companies may have a negative } \\
\text { effect on your CS. }\end{array}$ \\
\hline Credit Scores. (2019, November 22). https://www.consumer.ftc.gov/articles/0152-credit-scores \\
\hline
\end{tabular}

Ask your Agent which credit information factors had a negative impact on your CS. Insurers and credit scoring model developers, shown in Table 3, suggest several ways to improve your CS (Illinois Department of Insurance, 2009). 
TABLE 3

UNDERSTAND THE FOUR MAIN FACTORS TO IMPROVE YOUR CREDIT SCORE

\begin{tabular}{|l|l|}
\hline Factor One: & $\begin{array}{l}\text { Avoid late payments. Late payments, amounts owed, new credit applications, types of } \\
\text { credit, collections, charge-offs, and negative items such as bankruptcies, liens and } \\
\text { judgments. }\end{array}$ \\
\hline Factor Two: & $\begin{array}{l}\text { Use time effectively. Pay your bills on time. Pay at least the minimum balance due, on } \\
\text { time, every month. Work to reduce the amount you owe, especially on revolving debt } \\
\text { like credit cards. }\end{array}$ \\
\hline Factor Three: & $\begin{array}{l}\text { Limit new credit accounts. Several applications for credit in a short time will usually } \\
\text { have a negative effect on your CS. }\end{array}$ \\
\hline Factor Four: & $\begin{array}{l}\text { Be persistent. Your credit will improve with the proper behavior as long as you are } \\
\text { persistent and stay the course. }\end{array}$ \\
\hline Source: Illinois Department of Insurance. (2009). http://insurance.illinois.gov/General/how insurers use credit.pdf
\end{tabular}

\section{Review Your Credit Report Each Year for Free}

Under federal law, if you have been denied credit or insurance, if you are on welfare or unemployed, or if you are the victim of identity theft, you are entitled to a free copy of your credit report from the credit reporting bureaus. The three national credit bureaus are:

$\checkmark$ Equifax (http://www.credit.equifax.comor 800-685-1111)

$\checkmark$ Experian (http://www.experian.comor 888-397-3742)

$\checkmark$ Trans Union (http://www.transunion.comor 800-888-4213)

Most consumer groups suggest you get a copy of your credit report once a year and review it for errors, even if you have not been denied credit or insurance. As of March 1, 2005, consumers can get a free copy of his/her credit report from each of the three national credit bureaus (Equifax, Experian, and Trans Union) once every 12 months. You can Google http://www.annualcreditreport.com or call toll free 877-322-8228 to order reports. Use the Annual Credit Report Request Service (P.O. Box 105281 Atlanta, GA 30348-5281) forms, which can be printed from http://www.consumer.ftc.gov/topics/credit-and-loans.

Since the three national credit reporting bureaus do not share information with each other, if you correct an error on one report, it will not "fix" incorrect information on the other reports (Understanding How Insurers Use Credit Information," 2009).

\section{Tell the Credit Bureau About Any Errors}

If there is an error, report the error to the credit bureau. The credit bureau must investigate and respond within thirty days. They must contact the entity that reported the information to verify accuracy.

If the reporting entity agrees that the information is incorrect, or the information cannot be verified, the credit bureau must remove or update the information. The credit bureau must also provide a notice of correction to any creditor that has check your file in the last six months.

The credit bureau will not edit or remove the information if the information is proven correct. The FCRA will permit you to file a 100 -word statement explaining your side of the story, and the reporting bureau must include your statement with your credit information each time it is sent out. You should provide this information to your insurance company and ask if they will take it into account. When the errors have been addressed, you should obtain a copy of your credit report about three months later to ensure the incorrect information has not been reported again.

\section{Tell Your Insurance Company About Any Errors}

What can I do if I suspect that my credit report contains inaccurate or erroneous information that adversely affects my CS?

Be proactive and contact your insurer before the credit bureau investigates the errors. Request that the insurer wait to use your credit information after the errors are corrected. Although small errors will have little effect on your CS, large errors can make a significant impact to your insurance coverages or 
premium. Law requires the insurer to re-underwrite or re-rate you within 30 days after receiving the notice, and make any necessary adjustments.

Once you, or the consumer reporting agency, notifies the insurer that the dispute has been resolved in your favor your premiums will be lowered. If it is determined that you overpaid premium, the insurer is required to refund any overpayment you made for the past 12 months of coverage, or the actual policy period, whichever is shorter (Understanding How Insurers Use Credit Information,” 2009).

\section{IN SUMMARY, IS CREDIT SCORING JUSTIFIABLE}

Except in the states of California, Massachusetts, or Hawaii, many auto and home insurance companies utilize credit-based scoring in estimating risk and developing insurance rates. In calculating individual rates, credit scoring is only one of potentially hundreds of factors used by insurance companies. One could have an excellent or above average CS but several "at-Fault" accidents and or traffic violations. This would place him or her in a riskier category.

There has been and continues to be very contentious views regarding the use of credit scoring. Those who oppose the use of credit scoring argue that the use of CS penalize those who may have suffered financial misfortune through no fault of their own. Real life examples include but not limited to, economic downturns and or medical issues. These types of misfortune tend to adversely affect low income and minorities at higher rates. Insurers believe that credit scoring is blind to income and ethnic status. A 2007 study by the Federal Trade Commission concluded that the use of CSs "likely leads to African Americans and Hispanics paying relatively more for automobile insurance than non-whites and Asians". This can be attributed to the fact that as a group, African Americans and Hispanics tend to have lower CSs than non-Hispanic whites and Asians. As it relates to risk prediction, the use of credit scoring is the same for both groups. The FTC found that CSs were accurate in predicting the likelihood of an individual filing an auto insurance claim.

Several states have taken measures to shield consumers from the effects of credit-based scoring. The state of California prohibits insurer's use of credit scoring in rating automobile insurance premiums. California drivers may be at a loss since the state is among the top 10 most expensive states for auto insurance rates (Harrow, 2016).

Today, most insurance companies focus on at least thirty or more rating factors compared to only a few in the years past. Before the use of "many" factors, insurance companies would only use limited factors, such as age, driving record, garaging address, type of automobile, and marital status. Insurance companies argue that many drivers that may be negatively affected by the preceding factors, may actually be advantaged by the use of credit scoring, assuming that their personal credit rating is "good" to "excellent".

The facts are, roughly ninety percent of all auto and home insurance companies use credit scoring as one of the many rating factors. Although it is possible to purchase a policy without the consideration of a $\mathrm{CS}$, chances are your rate will be significantly higher. Policies that do not require credit scoring are generally sold by insurers that specialize in the "high-risk" category. By default or defacto, a client that purchase a policy from a "high-risk" insurer, places himself / herself in a high-risk pool and should expect higher insurance premiums (Why do insurance companies require a credit check, 2016).

\section{RECOMMENDATIONS FOR A BETTER RATE}

At the end of the day, the primary concerns for most consumers are the premium charged, the claims paying ability, and the type/amount of coverage provided. With credit scoring being only one of many factors involved in rate setting, individuals and families can still pay relatively moderate insurance premiums even with a compromised insurance CS. To find competitive rates, it will take a little research and planning. We make 10 recommendations for lowering the costs of credit. 


\section{Recommendation \#1}

Complete a comparative rate check every three to four years. We recommend three to four years because many carriers provide "loyalty" discounts that may apply to one's "current" insurance carrier. We recommend considering carriers from these sources, at least one Independent Agent (represents multiple carriers), one Captive Agent (represents one carrier, i.e. State Farm), and one Direct (represent a carrier that does not use an agent, i.e. Geico).

\section{Recommendation \#2}

The old adage, "you get what you pay for" is true in most cases when purchasing insurance coverage. We recommend a "financial rating" comparative check of the carriers being considered. The checks can be easily performed by checking with rating companies like AM Best. A nightmare situation evolves when one pays premiums for years, only to have the insurance company cut corners by engaging in such practices as encouraging repair shops to use after-market versus original manufacturer's equipment parts in an attempt to minimize cost. You should do a little research to get an idea of the company's reputation for "handling" claims. The respective state insurance department's website is a good place to begin your research (10 Ways to Lower Car Insurance Costs, 2017)

\section{Recommendation \#3}

The best way to save money on your premium is to simply have and maintain an excellent driving record and not file small claims. Each household driver taking a driver's training and or defensive driving course every four to five years will help and may carriers provide discounts for the classes.

\section{Recommendation \#4}

Getting an insurance quote "before" purchasing the car or home will arm you with invaluable knowledge for estimating the total cost of ownership. As typical consumers, our natural tendency is to secure a "great deal" or a "steal". In some instances, that "great deal" or "steal" may cost us a lot more than anticipated. An example is the simple fact that some automobile just cost more to insure than others. The cost to repair certain automobiles are much higher than others and the certain automobiles cause more damage than others involved in accidents. In the case of homeowners insurance, the location (coastal versus inland) and or age (five years versus fifty years) will have a significant bearing on the premium charged.

\section{Recommendation \#5}

The more "skin you have in the game", the lower your rate will be. The consumer can add "skin" by simply increasing the deductibles. Increasing the deductible from $\$ 500$ to $\$ 1000$ (auto) and or one percent to three percent (homeowners) will usually make a significant difference in the premium being charged.

\section{Recommendation \#6}

"Bundling" may also present significant savings. The operative language is "may". Some stand-alone auto and home insurers offer significantly better rates than multi-line carriers. If one does not mind using multiple carriers for home and auto, the saving may be worth the extra communication. Most Independent agents can provide a one-stop-shopping experience (9 Ways to Reduce Your Insurance Costs, 2014)

\section{Recommendation \#7}

Insurance companies often advertise the most popular discounts; however, most discounts are not advertised. We recommend the consumer request a list of available discounts for the insurers being considered. We recommend a "list" due to the nature and number that may be applicable to each individual situation, i.e. age (retiree), good grades, student away without car, multi-policy, occupation (teacher), payment in full etc. 


\section{Recommendation \#8}

Avoid a "lapse" in coverage. Almost all insurance carriers will penalize the consumer if there has been a lapse in coverage. With certain carriers, a lapse in coverage will result in ineligibility for coverage. We recommend that insurance premiums be paid on time. In the event of changing carriers, make sure the coverage from the new carrier is in effect "before" ending coverage with the current carrier.

\section{Recommendation \#9}

Know and understand the "exclusions" in the policy. Many "low cost" policies come with significant exclusions, i.e. certain drivers in the home (auto) or animal/roof/hurricane (home). Stated simply, do not forget the reason for buying insurance. Although one hope he or she will never need to use insurance, however, it should serve as a financial "life preserver" if it has to be activated.

\section{Recommendation \#10}

Last and certainly not least, monitor your credit. Most insurance carriers consider CSs when calculating rates. The consumer could end up paying up to 40 to 50 percent more for insurance if you have a low CS. We recommend the consumer be deliberate in addressing credit, in using and monitoring. Studies have shown a high correlation between ones CS and propensity to file insurance claims. Insurance companies also see a correlation between pass performance and future performance as it relates to premium payments (Top 10 Ways to Lower Your Car Insurance Bill, 2009).

\section{REFERENCES}

Clarke, W. (2009, May 12). Top 10 ways to lower your car insurance bill. Edmunds.com. Retrieved from https://www.edmunds.com/car-reviews/top-10/top-10-ways-to-lower-your-car-insurance-bill.html

Credit Scores. (2019, November 22). Federal Trade Commission: Consumer Information. Retrieved from, https://www.consumer.ftc.gov/articles/0152-credit-scores

Esurance.com. (2018, October 16). Your credit score doesn't affect your rate: Partially debunking a car insurance myth. Retrieved from, https://www.esurance.com/info/car/myth-your-credit-scoredoesnt-affect-your-insurance-rate

FICO. (2019, November 22). WIKIPEDIA: The Free Encyclopedia. Retrieved from, https://en.wikipedia.org/wiki/FICO

Harrow, R. (2016, April 25). Is your credit score affecting your insurance premiums? Forbes.com.

Hennelly, R. (2015, July 30). Why use credit scores to set car insurance rates? CBS News: MoneyWatch. Retrieved from, http://www.cbsnews.com/news/why-use-credit-scores-to-set-car-insurance-rates/ https://www.forbes.com/sites/robertharrow/2016/04/25/is-your-credit-score-affecting-yourinsurance-premiums/\#ca4a67820df6

Illinois Department of Insurance. (2009). Understanding how insurers use credit information. Retrieved from, http://insurance.illinois.gov/General/how_insurers_use_credit.pdf

National Association of Insurance Commissioners. (2012). Credit-based insurance scores: How an insurance company can use your credit to determine your premium. Retrieved from, http://www.naic.org/documents/consumer_alert_credit_based_insurance_scores.htm

9 ways to lower your insurance costs. (2019). Insurance Information Institute. Retrieved from, https://www.iii.org/article/nine-ways-to-lower-your-auto-insurance-costs

10 ways to lower car insurance costs: How to cut your premiums - but not your coverage (2017). Consumer Reports. Retrieved from, https://www.consumerreports.org/carinsurance/ ways-to-lower-car-insurance-cost

Why do insurance companies require a credit check? (2019, April 24). CarInsurance.com. Retrieved from, https://www.carinsurance.com/credit-check.aspx 